\title{
CHARACTERIZATION OF A PAPAIN-LIKE CYSTEINE-PROTEINASE ENCODED BY GENE 1 OF THE HUMAN CORONAVIRUS HCV 229E
}

\author{
Jens Herold, Volker Thiel, and Stuart G. Siddell \\ Institute of Virology and Immunology \\ University of Würzburg \\ Versbacher Strasse 7 \\ 97078 Würzburg, Germany
}

\section{ABSTRACT}

Expression of the coronaviral gene 1 polyproteins, pp1a and pp1ab, involves a series of proteolytic events that are mediated by virus-encoded proteinases similar to cellular papain-like cysteine-proteinases and the $3 \mathrm{C}$-like proteinases of picornaviruses. In this study, we have characterized, in vitro, the human coronavirus HCV 229E papain-like cysteineproteinase PCP 1 . We show that PCP 1 is able to mediate cleavage of an aminoterminal polypeptide, $\mathrm{p} 9$, from in vitro translation products representing the aminoproximal region of pp1a/pp1ab. Mutagenesis studies support the prediction of Cys1054 and His 1278 as the catalytic amino acids of the HCV 229E PCP 1, since mutation of these residues abolishes the proteolytic activity of the enzyme.

\section{INTRODUCTION}

The HCV 229E genome is a single-stranded, positive sense RNA comprised of approximately 27000 nucleotides. Gene 1 encompasses the 5 '-two thirds of the genome and encodes for proteins thought to be involved in viral replication and transcription (Herold et al., 1993). Gene 1 contains two large overlapping open reading frames, ORF 1a and ORF $1 \mathrm{~b}$, with the potential to encode for polypeptides of approximately $450 \mathrm{kDa}$ and 300 $\mathrm{kDa}$, respectively (Herold et al., 1993). In vitro studies suggest that the ORF lb gene product is expressed as a fusion protein by a (-1) ribosomal frameshifting event mediated by an element located at the junction of ORF la and ORF $1 \mathrm{~b}$ (Herold and Siddell, 1993). 
Computer-assisted analyses of the HCV 229E gene 1 sequence has revealed a number of putative functional domains within ppla and pplab. These include an RNA-dependent RNA-polymerase domain and a metal-binding/helicase domain, both encoded in ORF $1 \mathrm{~b}$, as well as domains indicative of papain-like cysteine-proteinases and a chymotrypsin-like cysteine-proteinases (3C-like proteinases) encoded by ORF 1a (Herold et al., 1993).

Recently, we have shown that an autoproteolytic activity is encoded within the aminoterminal 1315 amino acids of the HCV 229E ppla/pplab, a region that includes the predicted PCP 1 domain (Herold, 1995). The proteolytic activity could be blocked in vitro by $\mathrm{ZnCl}_{2}$ but not by leupeptin.

In this study, we have produced a polyclonal rabbit antiserum specific for the amino acids 41 to 250 of HCV 229E ppla/pplab. Using this antiserum, we have been able to show that the HCV 229E PCP 1 proteinase is responsible for the release of the aminoterminal polypeptide, $\mathrm{p} 9$, from $\mathrm{pp} 1 \mathrm{a} / \mathrm{pp} 1 \mathrm{ab}$ and we have determined, by mutagenesis analysis, the putative catalytic amino acids of this proteinase.

\section{MATERIALS AND METHODS}

\subsection{Preparation of Antigen and Antiserum}

A $632 \mathrm{bp} \mathrm{SphI/KpnI} \mathrm{cDNA} \mathrm{fragment,} \mathrm{representing} \mathrm{the} \mathrm{nucleotides} 412-1043$ of the genomic RNA of HCV 229E, was excised from the plasmid J12E6 (Herold et al., 1993) and ligated with $\mathrm{Sph} / \mathrm{KpnI}$ digested DNA of the bacterial expression vector plasmid QE30 (Diagen, Germany). The resulting plasmid, I1a.1, was transformed into competent JM109 bacteria and characterized by restriction enzyme analysis and sequencing of the cloning sites.

For bacterial expression of the recombinant polypeptide, plasmid Ila.1 was transformed into M15/pRep4 bacteria. The recombinant protein expressed from this plasmid comprises 230 amino acids: 12 amino acids at the aminoterminus that are encoded by the expression vector (including 6 consecutive histidines), 210 amino acids encoded by the HCV 229E RNA polymerase gene, corresponding to amino acids $41-250$ of ppla/pp $1 \mathrm{ab}$ and two vector-derived amino acids at the carboxy terminus. Expression and purification of this fusion protein, pHis(41-250), and immunization of rabbits was done as described previously (Ziebuhr et al., 1995). The resulting pHis(41-250) protein-specific antiserum is referred to as IS1720.

\subsection{Plasmids}

The construction of plasmid Pap has been described (Herold et al., 1996). Briefly, a cDNA representing the nucleotides 2244793 of the genomic RNA of HCV 229E was amplified by RT-PCR from poly(A) selected RNA from HCV 229E infected C16 cells and cloned into a BluescriptIISK + vector. The nucleotide sequence of Pap was determined and several PCR-derived nucleotide misincorporations were identified. In the context of this study, the change of a lysine codon AAA (Lys-1316) to a termination codon TAA is relevant.

\subsection{PCR}

Pap DNA (1ng) was used as a template for four different PCR reactions using the Elongase amplification system (Life Technologies, USA) as recommended by the manu- 
facturer. Oligonucleotide T7 (5'-AATACGACTCACTATAG-3') was the upstream primer, and the oligonucleotides I (5'-CACAAGTCACAGTGGTTGG-3'), II (5'GTGCTGATTGAATAGTCTTAC-3'), III (5'-GTTAGTCTGGTAATGACCAC-3') and IV (5'-GCAAGGTTCTCATTAGCA-3') were used as downstream primers. The cycle conditions were: initial denaturation, $94{ }^{\circ} \mathrm{C}$ for $30 \mathrm{~s} ; 30$ cycles at $94{ }^{\circ} \mathrm{C}$ for $30 \mathrm{~s}, 50{ }^{\circ} \mathrm{C}$ for $30 \mathrm{~s}$, $68{ }^{\circ} \mathrm{C}$ for $75 \mathrm{~s} / 1 \mathrm{~kb}$ to be amplified; final elongation step $72{ }^{\circ} \mathrm{C}$ for $10 \mathrm{~min}$. The PCR DNAs are referred to as PCR I to PCR IV and the encoded polypeptides are called, according to their length, pI-613, pII-956, pIII-1209 and pIV-1309.

\subsection{In Vitro Transcription and Translation}

RNAs were synthesized in vitro using the MEGAscript T7 Kit (Ambion, USA) and translated (100 ng per $\mu \mathrm{l}$ translation reaction) in a reticulocyte lysate in the presence of $\left[{ }^{35} \mathrm{~S}\right]$-methionine as described earlier (Herold et al., 1996). Aliquots $(2 \mu \mathrm{l})$ of the translation reaction were used for immunoprecipitation with IS1720 as described previously (Ziebuhr et al., 1995).

\subsection{Site-Directed Mutagenesis}

Site specific mutations were introduced into pPap by in vivo-recombination PCR as described (Herold and Siddell., 1993).

\section{RESULTS}

We have expressed an antigen, pHis(41-250), representing amino acids 41-250 of the HCV 229E ppla/pplab, which allows for a fast, single-step purification of the recombinant protein by affinity chromatography on Ni-NTA-agarose columns (Figure 1). The polypeptide has been used to immunize rabbits, resulting in the antiserum IS1720.

A recombinant plasmid, Pap, containing a T7 RNA polymerase promotor followed by the coding sequence of the aminoterminal 1315 amino acids of ppla/pplab was constructed. A series of PCR-DNAs (I-IV) were derived from pPap and subsequently transcribed and translated in vitro.. The translation products were then immunoprecipitated with IS1720. As expected, and as is shown in Figure 2, RNA derived from PCR I, PCR II and PCR III encoded for proteins with apparent molecular masses of $66 \mathrm{kDa}(\mathrm{pI}-613), 104$ $\mathrm{kDa}(\mathrm{pII}-956)$ and $133 \mathrm{kDa}$ (pIII-1209), respectively. PCR IV encodes for the aminoterminal 1.309 amino acids of the HCV 229E ppla/pplab and contains the predicted catalytic amino acids of the first papain-like cysteine-proteinase domain PCP 1. Upon translation of PCR IV-RNA a $9 \mathrm{kDa}$ polypeptide was detected, together with a number of higher molecular mass polypeptides. These polypeptides include products with apparent molecular masses of $143 \mathrm{kDa}$, the expected size of the PCR IV-RNA primary translation product, and $134 \mathrm{kDa}$, the expected size of the processed product.

Our interpretation of the data shown in Fig. 2 is that PCP 1 recognizes the full length translation product of PCR IV-RNA, releasing $\mathrm{p} 9$ and a processed polypeptide of 134 $\mathrm{KDa}$. Due to the position of $\mathrm{pHis}(41-250)$, relative to $\mathrm{pp} 1 \mathrm{a} / \mathrm{pp} 1 \mathrm{ab}$, we concluded that $\mathrm{p} 9$ represents the aminoterminal polypeptide of ppla/pplab. Using this in vitro approach, we are also able to position the carboxyterminal border of the active PCP 1 domain between the amino acids 1.209 and 1.309 of ppla/pplab. 


\section{A}
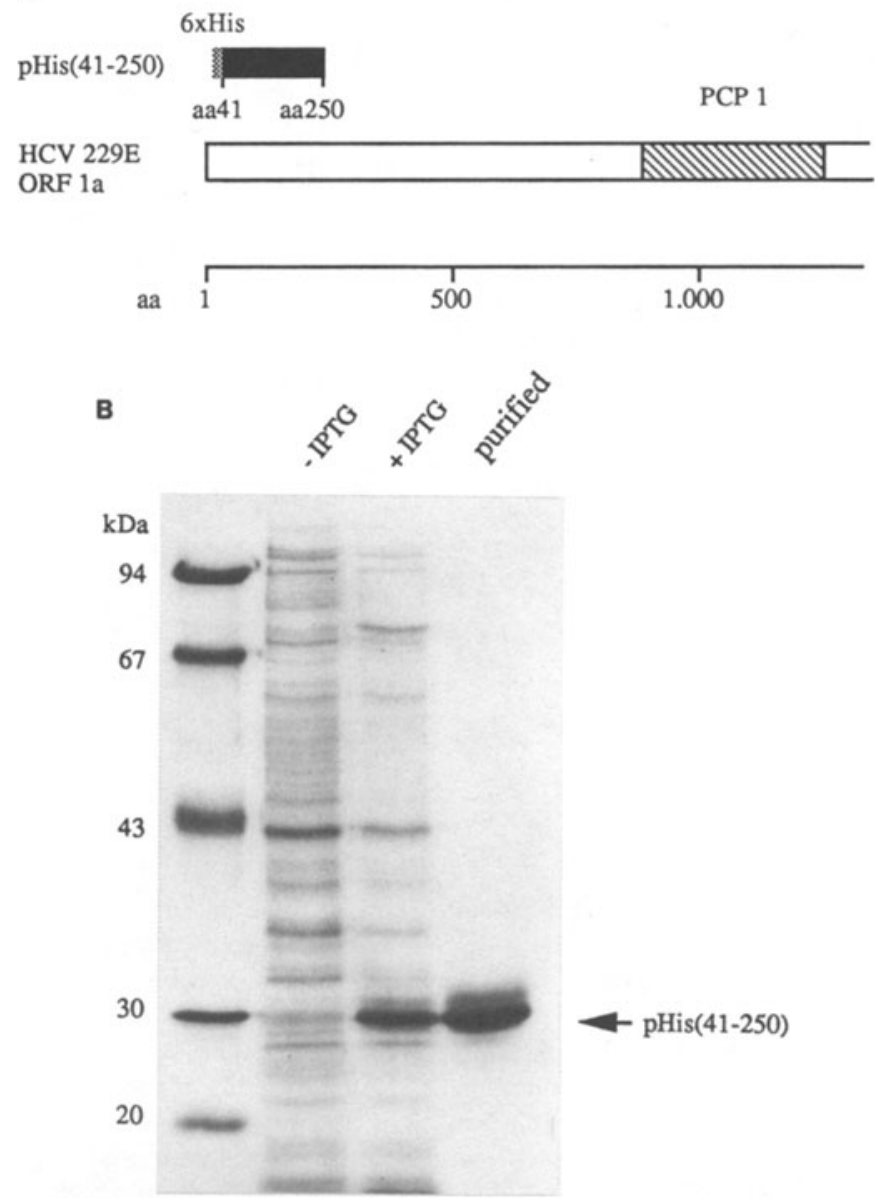

Figure 1. Expression and purification of pHis(41-250). (A) Schematic representation of pHis(41-250) in relation to the aminoproximal region of the HCV 229E ppla/pplab. (B) Cell lysates from non-induced and IPTG-induced bacteria and purified pHis $(41-250)$ were separated by SDS-PAGE in a $15 \%$ polyacrylamide gel.

In a further series of experiments, the codons for the cysteine residues Cys 962 and Cys 1054 and the histidine residues His 1205 and His 1278 have been mutated and the effect of these changes on proteolytic activity have been monitored (Figure 3). Upon transcription and translation of pPap-DNA, $\mathrm{p} 9$ and a processed form of the full length translation product (primary translation product $144 \mathrm{kDa}$, processed form $135 \mathrm{kDa}$ ) are detected . When Cys962 is changed to Gly (Cys962Gly) or His 1278 is changed to Gly (His1278Gly) or Val (His $1278 \mathrm{Val}$ ), the proteolytic processing remained unaffected. In contrast, when Cys 1054 was changed to Arg (Cys1054Arg), Gly (Cys1054Gly), or Ser (Cys1054Ser) and His 1205 was changed to Ala (His1205Ala) or Gly (His1205Gly), the generation of p9 was 


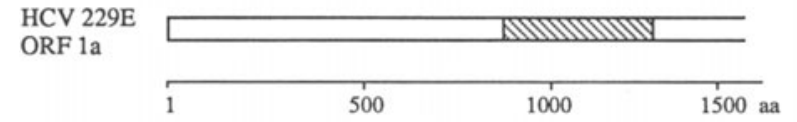

\section{$\mathrm{T} 7$}

\section{PCR I}

pI-613

$\mathrm{T} 7$

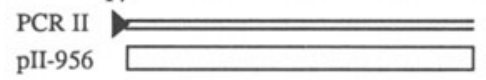

T7

\section{PCR III}

pIII-1209

$\mathrm{T} 7$

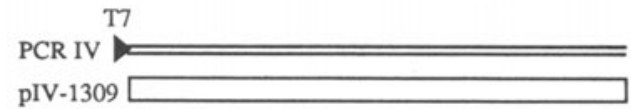

$143 \mathrm{kDa}$ pred.

mol. mass

p9

$66 \mathrm{kDa}$

$104 \mathrm{kDa}$

$133 \mathrm{kDa}$

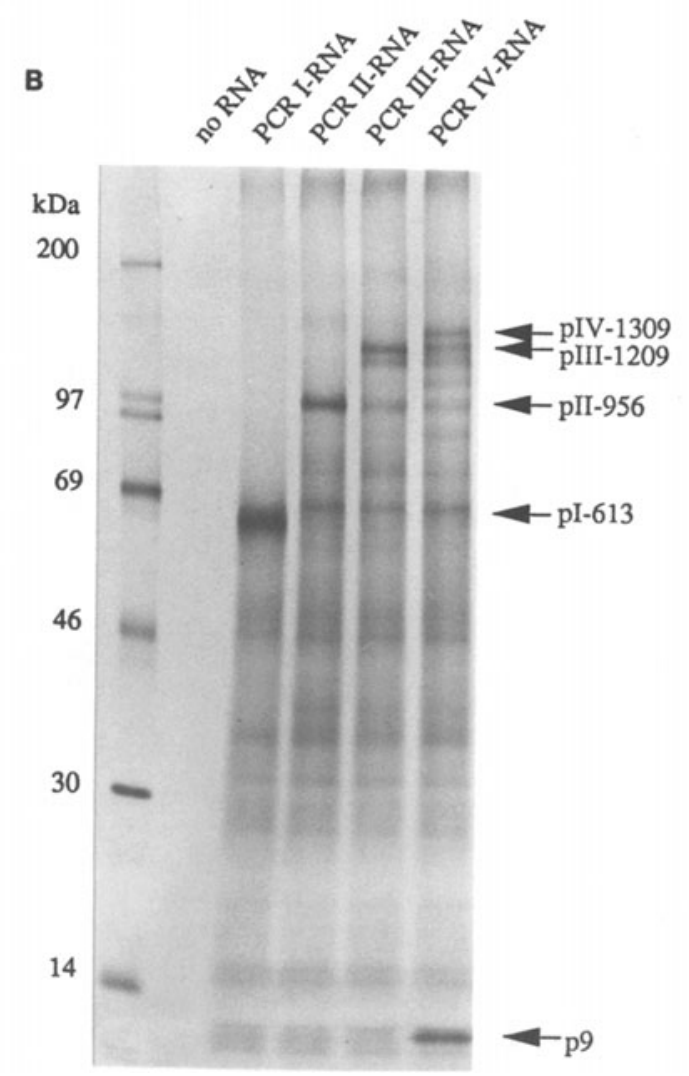

Figure 2. Mapping of the domain necessary for $\mathrm{p} 9$ processing. (A) Schematic representation of the HCV 229E ORF 1a, the PCR-DNAs and their predicted primary translation products. (B) In vitro transcription/translation of PCR-DNAs and immunoprecipitation of the translation products. The immunoprecipitated poylpeptides were separated by SDS-PAGE in 10-17.5\%-polyacrylamide gels. Protein molecular weight markers are indicated. 


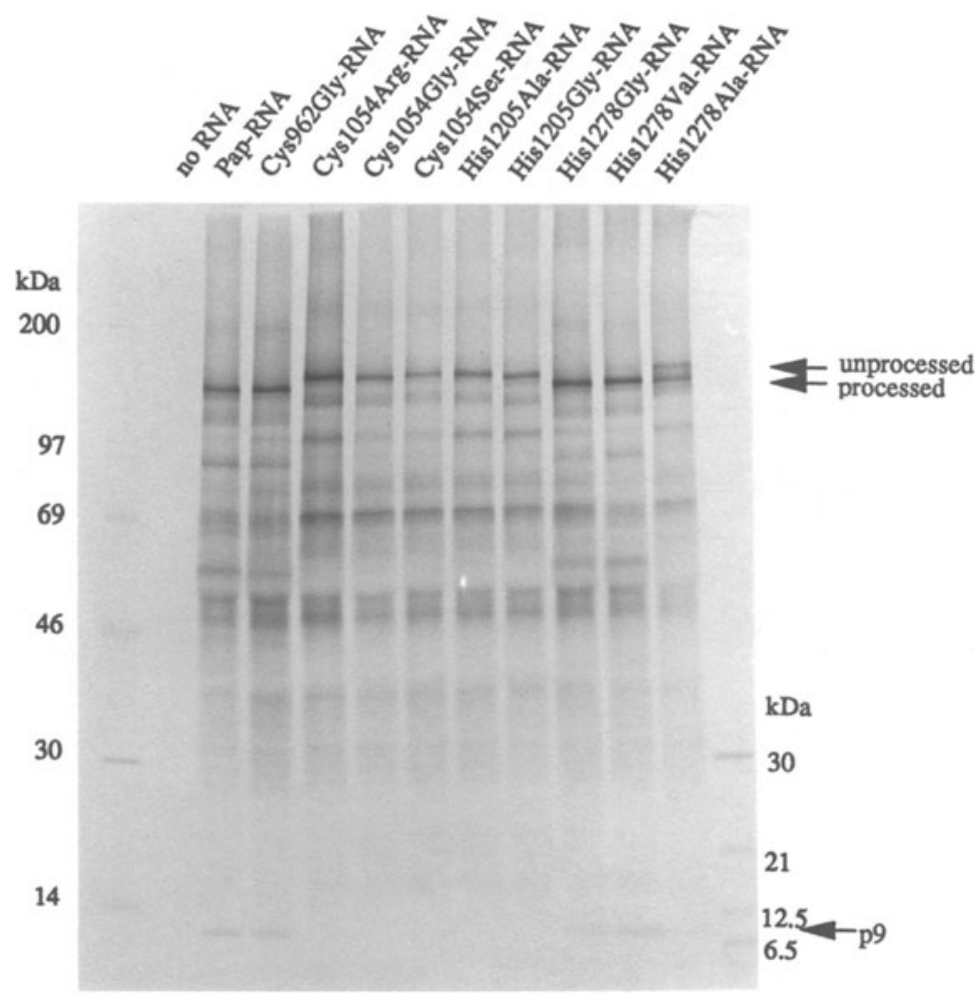

Figure 3. Mutagenic analysis of the HCV 229E-PCP 1. Pap RNA and RNAs derived from mutated DNAs were translated in reticulocyte lysates and the translation products were immunoprecipitated with IS1720. The proteins were analyzed by electrophoresis in a 10-17.5\% SDS-polyacrylamide gradient gel. Protein molecular weight markers are indicated.

completely abolished. The change His 1278 Ala decreased the extent of proteolytic processing. These data support the previous prediction of Cys1054 and His 1205 as the catalytic residues of HCV 229E PCP 1.

\section{DISCUSSION}

Proteolytic processing of non-structural gene products is thought to play a major role in the genesis of funtional replication complexes for many positive stranded RNA viruses (Dougherty and Semmler, 1993; Gorbalenya and Snijder, 1996). Although an adequate processing map of the coronaviral replicase polyproteins has not yet been established, considerable progress has been made in identifying the proteinases involved and their cleavage sites within the polyproteins. In this study, we have investigated proteolytic processing events within the aminoterminal part of the human coronavirus $229 \mathrm{E}$ ppla/pplab. 
Broadly, our results confirm a number of earlier studies that investigated the MHV PCP1 activity (Baker et al., 1989). It appears that the coronavirus PCP1 activity is responsible at least for the cleavage of a small polypeptide from the aminoterminus of ppla/pplab. In the case of MHV this polypeptide is p28. In the case of HCV 229E it is p9. At the present time, however, there is no indication of the possible function of these proteins. Immunofluorescence assays of HCV 229E-infected cells using the IS1720 antiserum has revealed a punctated pattern of staining in the perinuclear region. This may suggest that at least one of these proteins recognized by this serum remains associated with the virus replication complex (Heusipp et al., 1997).

\section{REFERENCES}

Baker, S. C., Shieh, C. K., Soe, L. H., Chang, M. F., Vannier, D. N., and Lai, M. M. C., 1989, Identification of a domain required for autoproteolytic cleavage of murine coronavirus gene A polyprotein, J. Virol. 63:3693-3699.

Dougherty, W. G., and Semler, B. L., 1993, Expression of virus-encoded proteinases: functional and strutural similarities with cellular enzymes, Micribiol. Rev. 57:781-822.

Gorbalenya, A. E., and Snijder, E. J., 1996, Viral cysteine proteinases, Perspectives in Drug Discovery and Design 6: $64-86$.

Herold, J., and Siddell, S.G., 1993, An elaborated pseudoknot is required for high frequency frameshifting during translation of HCV 229E polymerase mRNA, Nucleic Acids Res. 21:5838-5842.

Herold, J, 1995, Organization and Expression of RNA Polymerase Locus of the Human Coronavirus 229E, Ph.D. Thesis., University of Würzburg, Germany.

Herold, J., Siddell, S.G., and Ziebuhr, J., 1996, Characterization of coronavirus RNA polymerase gene products, Methods Enzymol. 275:68-89.

Herold, J., Raabe, T., Schelle-Prinz, B., and Siddell, S.G., 1993a, Nucleotide sequence of the human coronavirus 229E RNA polymerase locus, Virology 195:680-691.

Heusipp, G., Grötzinger, C., Herold, J., Siddell, S. G., and Ziebuhr, J., 1997, Identification and subcellular localization of a 41-kDa, polyprotein lab processing product in human coronavirus $229 \mathrm{E}$-infected cells, J. Gen. Virol. in press.

Ziebuhr, J., Herold, J., and Siddell, S. G., 1995, Characterization of a human coronavirus (strain 229E) 3C-like proteinase activity, J. Virol. 69:4331-4338. 